Volume 8, Issue 1, 257 - 265.

ISSN: 2165-8714

http://www.eu-jer.com/

\title{
Evaluation of Cultural Sensitivity in Healthcare Service among Nursing Students
}

\author{
Vesile Unver* \\ Acibadem Mehmet Ali Aydinlar \\ University, TURKEY
}

\author{
Yasemin Uslu \\ Acibadem Mehmet Ali \\ Aydinlar University, \\ TURKEY
}

\author{
Vildan Kocatepe \\ Acibadem Mehmet Ali Aydinlar \\ University, TURKEY
}

\author{
Sema Kuguoglu \\ Medipol University, \\ TURKEY
}

Received: November 25, 2018 - Revised: January 2, 2019 - Accepted: January 11, 2019

\begin{abstract}
The aim of the study evaluates cultural sensitivity in healthcare services among senior nursing students to patients with different cultural backgrounds. The study had a one-group pre-posttest model descriptive study design. Thirty-four nursing students taking the courses Emergency Care and Diabetes were included into the study. Standardized patients were used as a simulation technique. The difference between intercultural sensitivity scores before the simulation and those after the simulation was not statistically significant $(p>0.05)$. Even though there were no differences between intercultural sensitivity scores before the simulation and the scores after the simulation, simulation based education is an effective teaching method in enhancement of cultural sensitivity.
\end{abstract}

Keywords: Culturally sensitive care, simulation, nursing student.

To cite this article: Unver, V., Uslu, Y., Kocatepe, V., \& Kuguoglu, S. (2019). Evaluation of cultural sensitivity in healthcare service among nursing students. European Journal of Educational Research, 8(1), 257-265. doi: 10.12973/eu-jer.8.1.257

\section{Introduction}

Holistic nursing service that takes cultural values and beliefs of patients into consideration has increasingly become important in today's global world. Nurses should be aware of their responsibilities about providing holistic and individual-centered healthcare service to patients from all ethnic groups (Harrowing, Gregory, 0'sullivan, Lee \& Doolittle, 2012; Carey, 2011). Besides, prejudices and stereotypes in education of nursing students should be eliminated and self-evaluation of cultural awareness should be promoted (Mesler, 2014).

Today, parallel to the trend of globalization, each country is becoming multiculture. In response to the cultural diversity of the patients, systematic and more effective cultural education programs are needed to provide for culturally appropriate care for patients. It is reported that nursing students are unprepared for providing culturally competent care, although training in providing culture-sensitive care has been integrated into nursing curriculum (Choi \& Kim, 2018).

The importance of cultural sensitivity in nursing education should be underlined and the qualifications of nurses to deliver culturally sensitive service should be enhanced. The profession of nursing in a globalizing world requires individual-centered service to patients from different ethnic groups. Due to this reason, the importance of education of nurses, who have knowledge and skills to respond to cultural demands of society, is increasing day by day (Harrowing, Gregory, O'sullivan, Lee \& Doolittle, 2012; Carey, 2011). Studies have shown that simulation is the most reliable way of gaining knowledge and skills, but the use of simulations in social issues, for example in communication and cultural sensitivity, is less known (Dieckmann, Gaba \& Rall, 2007).

\section{Background}

In its general sense, cultural sensitivity may be described as the awareness about and usage of information about ethnic, cultural, gender or sexual preferences of individuals in order to explain attitudes and responses of individuals to their environment (American Nurses Association (p31) (American Nurses Association, 2015). In 2015, ANA dealt with culturally congruent practice in its book, entitled "Nursing: Scope and Standards of Practice". Here, culturally congruent practice is defined as" the application of evidence-based nursing that is in agreement with the preferred cultural values, beliefs, worldview and practices of the healthcare consumer and other stakeholders". Within the context of these

\footnotetext{
* Corresponding author:

Vesile Unver, Acibadem Mehmet Ali Aydinlar University, School of Nursing, Istanbul/Turkey.

$\bowtie$ vunver1@gmail.com
} 
standards, the importance of culturally sensitive healthcare service delivery by the nurses has been underlined in order to improve patient scores and decrease differences in healthcare services (Marion et al., 2016).

Aims and goals of cultural sensitivity in nursing education should be determined in order to increase cultural sensitivity of students (Creech et al., 2017). In line with these aims and goals, nursing educators should train qualified students so that the students may cope with the difficulties in the process of culturally sensitive healthcare service delivery (Chan \& Sy, 2016).

Communication plays a key role to improve healthcare quality of patients from different cultures. Improvement of intercultural sensitivity is highly important in order to communicate with the individuals with different cultural backgrounds and to solve their communication problems (Kuwano, Fukuda, \& Murashima, 2016). Although the impact of cultural behaviors, such as eye contact or body contact on nurse-patient relationship has not been well-researched, various studies revealed the important impacts of language barriers on healthcare services (Britton, 2004). Translators may be used to overcome language barriers. However, this measure may endanger patient safety due to translation problems, such as incomplete translation or commenting (Flores et al., 2003). Globalization, inequalities, demographic changes and wars have changed dynamics of migration in the last 20 years. The numbers of immigrants have been increasing day-by-day (United Nations Department of Economic and Social Affairs, 2015). Immigrants find it hard to learn the language of the host countries whereas health professionals are mostly unable to speak the language of immigrants (Marek, 2010). Language barrier has a negative impact on the communication between healthcare professionals and immigrants with different cultural backgrounds. Consequently, it poses an obstacle for immigrants to access healthcare and diminishes the quality of service that the immigrants receive (Weekers et al., 2018).

Enhancing cultural sensitivity is an important output in nursing education. However, education methods to maintain cultural sensitivity are limited. The main approach to enhance cultural sensitivity is the integration of the subject to nursing curriculum. Other methods include individual lectures, experiencing different cultures and simulation practices about different cultures (Creech et al., 2017).

Existing studies suggest that culturally sensitive education removes differences in terms of healthcare services delivered to patients (Brach \& Fraserirector, 2000) and improve healthcare quality so that it should be integrated to nursing curriculum (Waite \& Calamaro, 2010; Cruz et al., 2018). However, evaluation of the impact of education on cultural sensitivity is as important as intercultural nursing education itself (Chen \& Starosta, 2000). Due to this reason, this research aims to evaluate language barriers in culturally sensitive healthcare.

Aim

This study aims to evaluate language barriers in culturally sensitive healthcare provided by senior nursing students to patients with different cultural backgrounds.

Research questions

Research Question 1: Is there a difference between the pre-simulation and post-simulation intercultural sensitivity scores of participant students?

Research Question 2: What are the performance scores of the participants during the simulation practice?

Research Question 3: What is the relationship between post-simulation intercultural sensitivity scores of participants and their performance scores?

\section{Methods}

\section{Study Design}

This study had a one-group pre-posttest model descriptive study design. The last-year (n=54) interns studying at a nursing school in 2016-2017 academic year. Emergency and diabetes nursing are elective courses. 34 students taking these courses were included in the study. The sampling method was not used. The dependent variable of the study is the Intercultural Sensitivity Scores of students before and after the simulation.

\section{Participants}

The study sample included 34 nursing students taking the courses Emergency Care ( $\mathrm{n}=20)$ and Diabetes (n=14) and volunteering to participate in the study. All students were Muslim with Turkish origins. 91\% (n=31) was female and $9 \%$ was male. The ages of the students were between 21 and 25 years old and the mean was determined as $22.35 \pm 1.33$. The students were taking vocational English lessons. All students were in pre-intermediate English level. Only one student knew Arabic at the beginner level since the family had Arabic origins.

\section{Procedure}

To enhance the authenticity of the scenario, actors having different cultural backgrounds and speaking foreign languages were selected as standardized patients (SPs). To achieve environmental authenticity, triage areas were created in the emergency department (See photograph-1). One standardized patient was a Palestinian student with the 
native language of Arabic attending Erasmus program and the other patient was a person living in the USA and having the native language of English. Before implementation of the scenario, the SPs were given their scripts. They were offered one-hour education about the cues they would provide during the implementation, when to give these cues, features of their roles and the flow of the scenario. Expert opinion was obtained to determine whether the scenario reflected the real life. The scenario was first implemented by the researchers. In accordance with the expert opinion and difficulties encountered during the rehearsal, the scenario was revised.

Table 1. Content of the Scenario

Name: E. A. Gender: Male
Age: 42
Religion: Islam
Caregiver: -
Allergies: Unknown
Immunization: Unknown
Doctor: Assoc. Prof V. U. (facilitator)
Prior medical history: The patient, diagnosed as type II diabetes
one year ago, is taking the recommended treatment.

History of the current illness: E.A. is 42-year-old male patient immigrating to Turkey one year ago due to political conflicts and the civil war in Syria.

The patient, diagnosed as type II diabetes mellitus, was scheduled to receive treatment with metformin tablet. However, due to nonadherence to treatment and high glucose levels, Diamicron 60 mg once a day and Glikofaj 1gr two times a day were initiated three months ago. The patient, fasting during Ramadan, took his medications after having his meal at night. He presented to the emergency unit with hypoglycemia at about $4 \mathrm{pm}$. The patient cannot speak Turkish. In fact, his native language is Arabic. However, he can understand what is said in Turkish and speak a few Turkish words.

His reactions: He does not want female nurses to touch him. Since he does not want to break the fast, he refuses to eat anything and to have fluid administration. He strictly obeys Islamic principles and does not tolerate any violations of the principles. However, if appropriate explanations are made and if an appropriate approach is adopted, he can exhibit adherence to treatment.

\section{Learning objectives}

Performing primary and secondary evaluations of the patient, presenting to the emergency unit

Evaluations of the laboratory results and determining priorities (Blood glucose level: $70 \mathrm{mg} / \mathrm{dl}$ )

Performing treatment protocols for hypoglycemic emergency cases

Planning culture based care

Using effective communication strategies for patients with a

foreign language and culture (See following pictures)

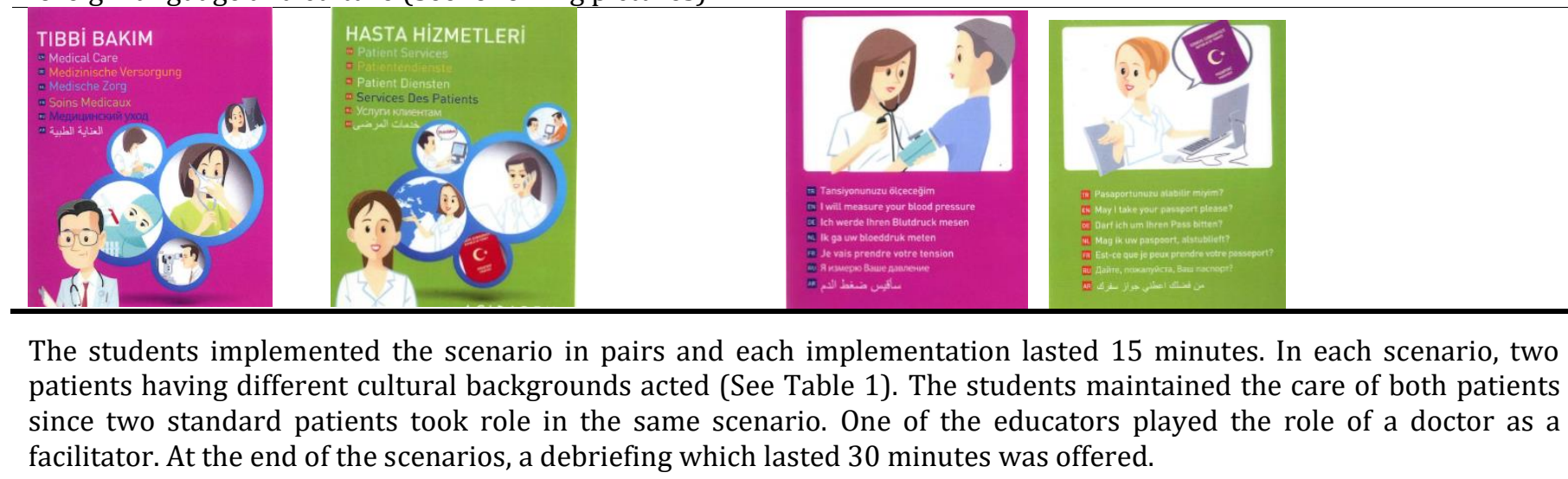

The students implemented the scenario in pairs and each implementation lasted 15 minutes. In each scenario, two patients having different cultural backgrounds acted (See Table 1). The students maintained the care of both patients since two standard patients took role in the same scenario. One of the educators played the role of a doctor as a facilitator. At the end of the scenarios, a debriefing which lasted 30 minutes was offered.

\begin{abstract}
Name: V. N. Gender: Female
Age: 52 Race and Nationality: White-American

Religion: Christian/Catholic

Caregiver: -

Allergies: Pollen, aspirin

Immunization: Unknown

Doctor: Assoc. Prof V. U. (facilitator)

Prior Medical History: She does not have a chronic disease. She was diagnosed as migraine five years ago. She has asthma and is taking her medications regularly.
\end{abstract}

History of the current illness: V. N. is 52 years old and came to Turkey for holiday one week ago. She had a headache during shopping. When the severity of her headache increased (VAS: 8), she had nausea and vomiting. Although she had medication for her headache, she couldn't use it. Therefore, she presented to the nearest emergency unit. She cannot speak or understand Turkish. Her native language is English.

Her reactions: Since she is getting treatment from staff with different cultural backgrounds, she is anxious, scared and panicked and is trying to express what she is experiencing. She is trying to say that she is allergic to aspirin and does not want to receive drugs. If appropriate explanations are made and if an appropriate approach is adopted, she can adhere to treatment.

\section{Learning Objectives}

Performing primary and secondary evaluations of the patient, presenting to the emergency unit

Planning culture sensitive care

Informing her about regular use of her medications

Using effective communication strategies for patients with a foreign language and culture (See following pictures) 


\section{Data Collection Tools}

Intercultural Sensitivity Scale (ISS) was utilized to determine cultural sensitivities of the students before and after the implementation of the scenario. In addition, the students' performances in the implementation of the scenario were observed and assessed by using Intercultural Sensitivity Assessment Checklist. The scale and the checklist allowed both objective and subjective evaluations of cultural sensitivity.

\section{Intercultural Sensitivity Scale (ISS)}

ISS was developed by Chen and Staros (2000) and involves five emotional subscales needed to be interculturally sensitive; i.e. interaction engagement, respect for cultural differences, interaction confidence, interaction enjoyment and interaction attentiveness. Interaction engagement included the items 1, 11, 13, 21, 22, 23 and 24 . Respect for cultural differences included the items 2, 7, 16, 18 and 20. Interaction confidence included the items 3, 4, 5, 6 and 10. Interaction enjoyment included the items 9,12 and 15. Interaction attentiveness included the items 14, 17 and 19. ISS is five-point scale and one corresponds to completely disagree, two disagree, three cannot decide, four agree and five completely agree. The items 2, 4, 7, 9, 12, 15, 18, 20 and 22 are scored in the reverse order (Chen \& Starosta, 2000). The validity and the reliability of the Turkish version of the scale were achieved by Bulduk et al. Like the original scale, it is a five-point Likert scale. It has 24 items, of which 15 are positive statements (supporting intercultural sensitivity) and nine are negative statements (not supporting intercultural sensitivity). The lowest total score of the scale is 24 , and the highest total score is 120 . The increase in the total score obtained from the scale shows that the level of intercultural sensitivity has increased. According to psychometric analysis results conducted by Bulduk et. al., the scale is composed of five factors similar to the original. The scale's test-retest consistency correlation coefficient was found as 0.85 , cronbach $\alpha$ internal consistency coefficient was found as 0.72 (Bulduk et al., 2011).

\section{Intercultural Sensitivity Assessment Checklist}

Intercultural Sensitivity Assessment Checklist was developed by the researchers to assess the students' performances in the implementation of the scenario. It was composed of 17 items. The students' performances were assigned the scores two (Yes), one (partial) and zero (None). The lowest and the highest scores for the checklist are zero and 34 respectively. Expert opinion about the items in the checklist was obtained and it was piloted during the rehearsal of the scenario.

\section{Ethical Consideration}

Ethical approval was taken from the ethical committee of the university where the study was conducted (Ethical approval number: 2017/13-3)

\section{Statistical Analysis}

Data was analyzed by using the Statistical Package Program for the Social Sciences (SPSS, Inc., Chicago, IL, USA) for Windows version 18.0. The normality of data was tested with Kolmogorov-Smirnov, test. The descriptive statistics mean, standard deviation, minimum-maximum values, frequency and percentage were utilized for analysis of the data. Since the variables were at normal range in "The Relation Between Intercultural Sensitivity Scores after the Simulation and Performance Scores" assessment, the Pearson correlation test was used as a parametric test. In the "Comparison of Intercultural Sensitivity Scores before the Simulation and the Scores after the Simulation" assessment, Paired Sample $t$ test, which is the parametric test performed in two different conditions, was used in the dependent sample. A p value of $<0.05$ was considered statistically significant.

\section{Results}

Table 2. Comparison of Intercultural Sensitivity Scores before the Simulation and the Scores after the Simulation

\begin{tabular}{|c|c|c|c|c|c|}
\hline \multirow[b]{2}{*}{ Intercultural sensitivity scale } & \multicolumn{2}{|c|}{ Before simulation } & \multicolumn{2}{|c|}{ After simulation } & \multirow[b]{2}{*}{ Statistics* } \\
\hline & Mean & SD & Mean & SD & \\
\hline Interaction engagement & 25.82 & 2.47 & 25.59 & 2.96 & $\mathrm{t}=.379 ; \mathrm{p}=.707$ \\
\hline Respect for cultural differences & 16.29 & 1.51 & 16.68 & 2.14 & $\mathrm{t}=-.788 ; \mathrm{p}=.436$ \\
\hline Interaction confidence & 15.68 & 1.63 & 15.62 & 2.24 & $\mathrm{t}=.123 ; \mathrm{p}=.903$ \\
\hline Interaction enjoyment & 7.79 & 2.17 & 8.44 & 2.83 & $\mathrm{t}=-1.179 ; \mathrm{p}=.247$ \\
\hline Interaction attentiveness & 11.62 & 1.58 & 11.47 & 1.74 & $\mathrm{t}=.373 ; \mathrm{p}=.711$ \\
\hline Total & 77.21 & 4.07 & 77.79 & 6.10 & $\mathrm{t}=-.464 ; \mathrm{p}=.646$ \\
\hline
\end{tabular}

*Paired Sample t test

Table 2 presents a comparison of intercultural sensitivity scores before the simulation and the scores after the simulation. The difference between intercultural sensitivity scores before the simulation and those after the simulation was not statistically significant $(p>0.05)$. 
Table 3. Results of the Students' Performances

\begin{tabular}{|c|c|c|c|c|c|c|}
\hline \multirow[b]{2}{*}{ Items } & \multicolumn{3}{|c|}{ Yes } & Partly & \multicolumn{2}{|r|}{ None } \\
\hline & $\mathbf{N}$ & $\%$ & $\mathbf{n}$ & $\%$ & $\mathbf{n}$ & $\%$ \\
\hline $\begin{array}{l}\text { He/She seems to be happy with communicating with people with different } \\
\text { culture }\end{array}$ & 5 & 14.71 & 21 & 61.76 & 8 & 23.53 \\
\hline He/She respects opinions of people with different culture & 18 & 52.94 & 16 & 47.05 & - & - \\
\hline He/She is confident when communicating with people with different culture & 3 & 8.82 & 17 & 50 & 14 & 41.18 \\
\hline He/She has difficulty in talking to people with different culture & 24 & 70.59 & 9 & 26.47 & 1 & 2.9 \\
\hline He/She knows how to communicate with people with different culture & 2 & 5.88 & 23 & 67.65 & 9 & 26.47 \\
\hline He/She used aides necessary for communication & 6 & 17.65 & 24 & 70.59 & 4 & 11.76 \\
\hline He/She respects cultural values of people with different culture & 15 & 44.12 & 19 & 55.88 & - & - \\
\hline $\begin{array}{l}\text { He/She seems nervous while communicating with people with different } \\
\text { culture }\end{array}$ & 18 & 52.94 & 15 & 44.12 & 1 & 2.9 \\
\hline He/She is confident while communicating with people with different culture & 2 & 5.88 & 18 & 52.94 & 14 & 41.18 \\
\hline $\begin{array}{l}\text { He/She takes time before making judgement about people with different } \\
\text { culture (thinking before making a decision) }\end{array}$ & 2 & 5.88 & 24 & 70.59 & 8 & 23.53 \\
\hline $\mathrm{He} /$ She is courageous when he/she is with people with different culture & 6 & 17.65 & 15 & 44.12 & 13 & 38.24 \\
\hline He/She is openminded towards people with different culture & 10 & 29.41 & 20 & 58.82 & 4 & 11.76 \\
\hline He/she treats people with different culture politely & 16 & 47.05 & 16 & 47.05 & 2 & 5.88 \\
\hline He/She respects types of behavior of people with different culture & 16 & 47.05 & 17 & 50 & 1 & 2.9 \\
\hline $\begin{array}{l}\text { He/She tries to collect as much information as possible about people with } \\
\text { different culture }\end{array}$ & 9 & 26.47 & 8 & 23.53 & 17 & 50 \\
\hline $\mathrm{He} /$ She has been able to collect culture sensitive data & 5 & 14.71 & 17 & 50 & 12 & 35.29 \\
\hline $\begin{array}{l}\text { He/She has performed appropriate culturally sensitive nursing } \\
\text { interventions }\end{array}$ & 10 & 29.41 & 23 & 67.65 & 1 & 2.9 \\
\hline
\end{tabular}

Table 3 shows the results of the students' performances observed by the educators during the simulation. Fifty-twopoint ninety-four percent of the students respected opinions of the people from different cultural backgrounds and $67.65 \%$ of the students knew how to communicate with the people from different cultural backgrounds. Sixty-onepoint seventy-six percent of the students did not appear happy with communicating with people from different cultural backgrounds, $70.59 \%$ of the students had difficulty in speaking and partly used the material necessary for communication, but $29.4 \%$ of the students completely performed appropriate culturally sensitive nursing interventions.

Table 4. The Relation between Intercultural Sensitivity Scores after the Simulation and Performance Scores

\begin{tabular}{lrr}
\hline & Intercultural Sensitivity Scores after the & Performance \\
Simulation & 1 \\
Intercultural Sensitivity Scores after the & & \\
Simulation & $\mathrm{p}=.547$ \\
Performance Scores & $\mathrm{r}=.112$ \\
\hline
\end{tabular}

r: Pearson correlation test

Table 4 shows the relation between intercultural sensitivity after the simulation and performance. There was no statistically significant relation between the intercultural sensitivity scores after the simulation and the performance scores $(\mathrm{p}>0.05)$.

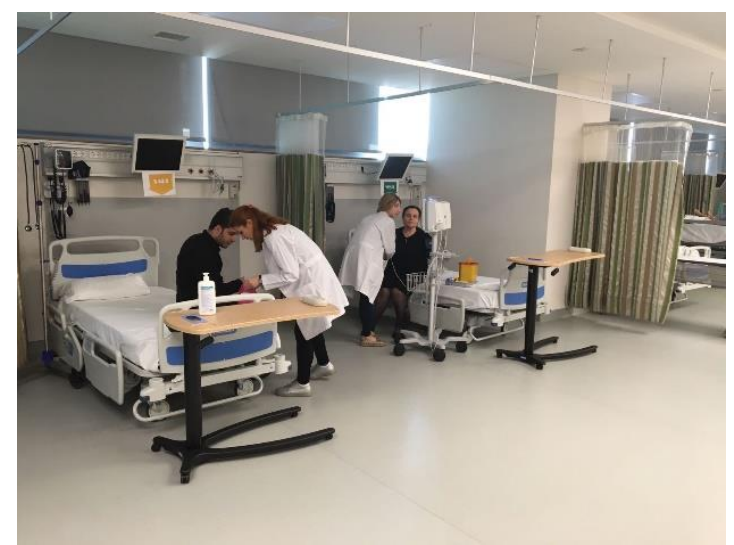

Photograph-1 


\section{Discussion}

At present, with changes in cultural structures of countries, nursing scholars attempt to integrate intercultural sensitivity to nursing curricula so that culturally sensitive care can be offered. Acquiring knowledge is not sufficient on its own to provide culturally sensitive care (Roberts, Warda, Garbutt \& Curry, 2014). Nursing scholars take the responsibility of enabling nursing students as potential nursing force able to decrease or eliminate inequalities to offer culturally sensitive care by recognizing similarities and differences between cultures (San Ozkara, 2015). The educators contribute to development of cultural sensitivities and cultural competencies of students by using different teaching methods.

In the present study, no significant difference was found between cultural sensitivity scores before the simulation and those after the simulation. Garrido et al. (2014) in their study did not show a significant change in the students' scores for general knowledge, cognitive awareness, research issues and patient care and/or clinical issues after an interprofessional simulation using SPs. In the current study, the students' cultural sensitivity scores were high before the simulation (77.21 4 4.07). The total scores for cultural sensitivity only slightly increased after the simulation (77.79 \pm 6.10$)$, contrary to the expectations. In fact, it was anticipated that the cultural sensitivity scores would be significantly higher after the simulation as compared with the scores before the simulation. Compatible with this finding, many studies have revealed that nurses have high cultural sensitivity scores (Meydanlioglu, Arikan \& Gozum, 2015). Yilmaz et al. (2017) reported that the participants received $84.01 \pm 9.1$ for cultural sensitivity. The high cultural sensitivity scores in the present study can be explained by the fact that cultural sensitivity is dealt with in detail in the nursing curriculum of the school where the study was conducted.

It was surprising that high cultural sensitivity levels did not have an influence on the students' performances during the simulation based education (See Table 2). It may be that the students were exposed to such simulation based education after theoretical courses for the first time. The most important difficulty experienced by the students during the simulation was related to communicating with the patients (See Item 4 in Table 2). It can be attributed to language barriers. It has also been reported in the literature that language barriers prevent health professionals from communicating with patients with different cultural backgrounds (Taylor, Nicolle \& Maguire, 2013). In a study by Guvenc et al. (2016), simulation based education using SPs was considered as an appropriate active education method for coping with language barriers of students. A study by Perry et al. (2015) pointed out that e-simulation effective methods that participants are understanding individuals who are language barriers. In the present study, the simulation allowed the students to experience difficulties they are likely to encounter when communicating with people speaking a foreign language. The students were taking the course English for Nurses. Therefore, the simulation provided the students with feedback about to what extent they put their language skills into practice.

The students' performance outcomes presented in Table 2 yields evidence for their cultural competence. The students had difficulty in communicating with the patients and obtaining culturally sensitive data and got panicked quickly. These outcomes indicated that they were partially successful in performing culturally sensitive nursing interventions. In a study using American-Norwegian SPs by Grosman et al. (2012) about cultural awareness of the students, while American students focused on verbal and nonverbal communication skills to understand the patients, Norwegian students focused on importance of speaking more than one language. The results of their study are of importance in that they emphasize communication skills in terms of elimination of language barriers while offering culturally sensitive care (Grossman et al., 2012). Like the Norwegian students in Grossman et al.'s study, the students in the present study underlined the importance of learning a foreign language. The difference between American students and Norwegian students might have been due to frequent use of the body language in communication caused by multicultural structure of the USA. Therefore, simulation based education is crucial in terms of creating awareness about the issue. In a review by San Ozkara (2015), clinical simulations have been reported to be an effective teaching strategy in integration of cultural awareness and sensitivity into nursing curricula. The results of the present study also showed that simulation based education was a teaching method enhancing awareness of the students about cultural sensitivity and allowing the students to put their theoretical knowledge into practice.

\section{Conclusion}

With globalization, and immigrations due to recent wars, societies change into multicultural structures. Providing safe and quality health services is based on health services that serve cultural and language diversity. It is important to increase cultural sensitivity to prevent inequalities in health care and to maintain patient safety during these changes. It is thought that simulation practice may be an alternative method in the development of cultural sensitivity. It is recommended to repeat the study in different and large sample groups.

\section{Limitation}

The results of the study cannot be generalized since one group is planned in the pre-posttest design. In the content of the scenario, handling the patients with language and religion differences and standardized patient use in the method were the only limitations of the research. 


\section{Acknowledgement}

We would like to thank our standardized patient.

\section{References}

American Nurses Association. (2015). Societal, Cultural, and Ethical Dimensions Describe the Why and How of Nursing. Nursing: Scope and standards of practice. Nursing: Scope and Standards of Practice (3 ${ }^{\text {rd }}$ ed., pp. 31-36). Silver Spring, MD: American Nurses Publishing

Brach, C., \& Fraserirector, I. (2000). Can cultural competency reduce racial and ethnic health disparities? A review and conceptual model. Med Care Res Rev, 57(supplement 1), 181-217.

Britton, C.V. (2004). American Academy of Pediatrics Committee on Pediatric Workforce. Ensuring culturally effective pediatric care: Implications for education and health policy. Pediatrics, 114(6), 1677-1685.

Bulduk, S., Tosun, H., \& Ardic, E. (2011). Measurement Properties of Turkish Intercultural Sensitivity Scale Among Nursing Students. Turkiye Klinikleri J Med Ethics, 19(1), 25-31.

Carey, R. E. (2011). Cultural competence assessment of baccalaureate nursing students: An integrative review of the literature. Int J Humanit Soc Sci, 1(9), 258-266.

Chan, J. C., \& Sy, P.Y. (2016). The relationships among personality, intercultural communication, and cultural selfefficacy in nursing students. J Res Nurs, 24(4), 286-290.

Chen, G.M. \& Starosta, W.J. (2000). The development and validation of the intercultural sensitivity scale. Human Communication, 3, 1-15.

Choi, J.S. \& Kim, J.S. (2018). Effects of cultural education and cultural experiences on the cultural competence among undergraduate nursing students. Nurse Educ Pract, 29, 159-162.

Creech, C., Filter, M., Wehbe-Alamah, H., McFarland, M.R., Andrews, M., \& Pryor, G. (2017). An intervention to improve cultural competence in graduate nursing education. Nurs Educ Perspect, 38(6), 333-336.

Cruz, J.P., Aguinaldo, A.N., Estacio, J.C., Alotaibi, A., Arguvanli, S., Cayaban, A.R.R. ... Sebaeng, J. A. (2018). Multicountry perspective on cultural competence among baccalaureate nursing students. J Nurs Scholarsh, 50(1), 92-101.

Dieckmann, P., Gaba, D., \& Rall, M. 2007. Depeening the Theoritical Foundation of Patient Simulation as Social Practice. Sim Healthcare, 2(3), 183-193.

Flores, G., Laws, M.B., Mayo, S.J., Zuckerman, B., Abreu, M., Medina, L., \& Hardt, E.J. (2003). Errors in medical interpretation and their potential clinical consequences in pediatric encounters. Pediatrics, 111(1), 6 -14.

Garrido, M., Dlugasch, L., \& Graber, P.M. (2014). Integration of interprofessional education and culture into advanced practice simulations. Clin Simul Nurs, 10, 461-469.

Grossman, S., Mager, D., Opheim, H.M. \& Torbjornsen, A. (2012). A bi-national simulation study to improve cultural awareness in nursing students. Clin Simul Nurs, 8, e341-e346.

Guvenc, G., Unver, V., Basak, T., Yuksel, C., Ayhan, H., Kok, G. ... Iyigun, E. (2016). Turkish senior nursing students' communication experience with English-speaking patients. J Nurs Educ, 55(2), 73-81.

Harrowing, J. N., Gregory, D.M., O'sullivan, P.S., Lee, B. \& Doolittle, L. (2012). A critical analysis of undergraduate students' cultural immersion experiences. Int Nurs Rev, 59(4), 494-501.

Kuwano, N., Fukuda, H., \& Murashima, S. (2016). Factors affecting professional autonomy of Japanese nurses caring for culturally and linguistically diverse patients in a hospital setting in Japan. J Transcult Nurs, 27(6), 567-573.

Marek, M. (2010). Poverty and social exclusion in the WHO European Region: health systems respond. Copenhagen, WHO Regional Office for Europe, 12.

Marion, L., Douglas, M., Lavin, M., Barr, N., Gazaway, S., Thomas, L. \& Bickford, C., (2016). Implementing the New ANA Standard 8: Culturally Congruent Practice. The Online Journal of Issues in Nursing, 22(1), 9-18.

Mesler, D.M. (2014). A comparative study of cultural competence curricula in baccalaureate nursing programs. Nurse Educ, 39(4), 193-198.

Meydanlioglu, A., Arikan, F. \& Gozum, S. (2015). Cultural sensitivity levels of university students receiving education in health disciplines. Advances in Health Sciences Education, 20(5), 1195-204.

Perry, A., Woodland, L. \& Brunero, S. (2015). eSimulation: A novel approach to enhancing cultural competence within a health care organisation. Nurse Educ Pract, 15(3), 218-24. 
Roberts, S.G., Warda, M., Garbutt, S., \& Curry, K. (2014). The use of high-fidelity simulation to teach cultural competence in the nursing curriculum. J Prof Nurs, 30(3), 259-65.

San Ozkara, E. (2015). Using Clinical Simulation to Enhance Culturally Competent Nursing Care: A Review of the Literature. Clin Simul Nurs, 11, 228-243.

Taylor, S.P., Nicolle, C. \& Maguire, M., (2013). Cross-cultural communication barriers in health care. Nurs Stand, 27(31), 35-43.

United Nations Department of Economic and Social Affairs. International Migration Report 2015. New York: United Nations.

Waite, R. \& Calamaro, C.J. (2010). Cultural competence: A systemic challenge to nursing education, knowledge exchange, and the knowledge development process. Perspect Psychiatr Care, 46(1), 74-80.

Weekers, J., López Acuña, D., Gijon Sanchez, M.T., Pulido, S.P., Kolehmainen Aitken, R.L. \& Petrova-Benedict, R. Developing a public health workforce to address migrant health needs in Europe. Retrieved March 20, 2018, from https://migrationhealthresearch.iom.int/developing-public-health-workforce-address-migrant-health-needseurope-0.

Yilmaz, M., Tokso, S., Direk, Z.D., Bezirgan, S., \& Boylu, M. (2017). Cultural sensitivity among clinical nurses: A descriptive study. Journal of Nursing Scholarship, 49(2), 153-161. 
APPENDIX:

NUMBER: ATADEK-2017/13

ISSUE: Decision of Ethical Committee

Honorable Assistant Professor Vesile Unver, Instructor Yasemin Uslu, Instructor Vildan Kocatepe, Prof. Dr, Sema Kuḡuoḡlu

The project titled " THE EFFECTIVENESS OF THE SIMULATION IN THE DEVELOPMENT OF INTERCULTURAL SENSITIVITY IN NURSING STUDENTS", which you are responsible for, was discussed at the Atadek Board Meeting dated 03.08.2017 and numbered 2017/13, and the medical ethics were approved in accordance with the decision number $2017-13 / 3$.

Prof.Dr, Güldal Süyen

ATADEK Vice Chairman

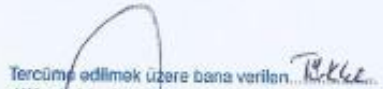

Tercumf odilmek uzere bana verilan $14<<<$. dilingakice Ast//Fotokopi/Faks belgeyi ing dillife im vo doğru olarak adimizi beyą edentio

Noter Yaminli Mútorcimi

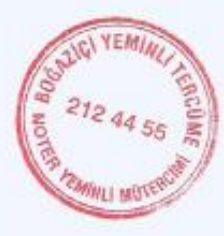

